\title{
Stepwise Management of Necrotizing Enterocolitis Could Improve Outcome of this Life-Threatening Disease
}

Abdel Maksod YH, Shahin AM, Ahmed $\mathrm{H}^{*}$ and Aabdelwahab MB

Departments of Pediatrics and General Surgery, Faculty of Medicine, Benha University, Egypt

\begin{abstract}
Objectives: To present various lines of management of infants with necrotizing enterocolitis (NEC) and to outline its outcome.

Patients and Methods: This prospective study included 127 neonates met Bell' s criteria for NEC diagnosis. All neonates were managed at NICU. Whenever indicated emergency laparotomy (EL) was performed. Medical management included no oral feeding, gastric suction, parentral nutrition, intravenous antibiotic therapy and cardiorespiratory support till patients start to thrive. Then, enteral feeding tolerance was tested and was started with mothers' milk given gradually. Bedside diagnostic mini-laparoscopy was performed for non-responders to medical intervention and if possible, dealing with pathology was conducted. Postoperative care was provided at NICU and patients were monitored for full recovery, development of additional morbidities or death.
\end{abstract}

Results: Thirty-nine patients required EL, while 88 patients underwent the medical intervention trial. Fifty-four cases responded to medical treatment and tolerated oral feeding within a mean duration of $39.3 \pm 8.4$ days. Bedside laparoscopy was performed for 34 non-responders and was therapeutic in 10 and preparatory for EL in 6 and reduced the need for EL in 18 cases. Fifty-seven patients tolerated oral feeding and started to thrive uneventfully, while 70 patients developed additional morbidities; 19 after medical and 51 after surgical intervention. Thirty-five patients died; 5 after medical and 30 after surgical intervention with significantly higher success rate and lower morbidity and mortality rates among patients had medical intervention compared to patients had surgical intervention.

Conclusion: Medical treatment and early gradual entral feeding with breast milk provided success rate of $61.4 \%$. Bed-side laparoscopy is promising adjuvant diagnostic and therapeutic modality for non-responders to medical intervention. Mortality rate was significantly higher with surgical interference, so could be preserved only whenever indicated.

Keywords: Necrotizing enterocolitis; Medical treatment; Nutritional support; Laparoscopy

\section{Introduction}

Necrotizing enterocolitis (NEC) is the most common lifethreatening gastrointestinal emergency experienced by premature infants cared for in the Newborn Intensive Care Unit (NICU) [1]. The incidence of NEC is inversely correlated to gestational age (GA) and birth weight (BW). Low BW premature infants are affected by NEC at a prevalence as high as $15 \%$ of all infants cared for in the NICU. More than $11 \%$ of infants born at BW below 750 grams will develop NEC. Hypotension within a week of life is significantly related to NEC [2].

The process leading to NEC is thought to be preceded by an ischemic or toxic event that causes damage to the immature gastrointestinal mucosa and loss of mucosal integrity [3]. The initiation of enteral feedings allows for bacterial proliferation at which time the damaged mucosa is invaded by gas-producing bacteria. This process may lead to necrosis which can cause either perforation of the bowel or sepsis [4] and then may often lead to sepsis caused by translocation of gut colonizing nosocomial pathogens in the peritoneum and/or blood [5].

The changes of the intestinal microcirculation in implicated in pathogenesis of NEC. Intestinal microcirculatory regulation is controlled by a balance of vasoconstrictor forces mediated primarily by endothelin-1 and vasodilator forces mediated primarily by nitric oxide. The balance shifting toward increased vasoconstriction is associated with intestinal injury and progress to NEC [6]. Intestinal ischemia has shown to cause activation of the inflammatory cascade, which is known as the final common pathway of intestinal injury [7].
Intestinal inflammation results in release of different categories of biomarkers of NEC including non-specific mediators of the inflammatory cascade, e.g. acute phase reactants, chemokines, cytokines, and cell surface antigens, enhanced non-specific biomarkers, and specific gut-associated proteins [8]. Inflammatory mediators often lead to an unfavorable response by the immature intestine, and in turn determine the symptoms observed, the severity of the illness, and the clinical outcome for the patient [9].

Primary prevention of NEC should be the priority, since NEC frequently progresses from nonspecific signs, to extensive necrosis within a matter of hours [10]. Despite many advances in the management of the critically ill neonate, the attempts at determining best treatment for NEC have been elusive, and unfortunately, the overall survival has not improved [10]. Medical management of NEC is largely supportive and likely does not modify the etiopathogenesis of this disease. Antenatal steroids, human milk feedings, adoption of standardized feeding regimens, and probiotics hold promise for prevention of NEC

*Corresponding author: Ahmed H, Departments of Pediatrics and Genera Surgery, Faculty of Medicine, Benha University, Egypt, Tel: 20133231011; E-mail: hsurgeon71@gmail.com

Received February 12, 2016; Accepted May 05, 2016; Published May 15, 2016

Citation: Abdel Maksod YH, Shahin AM, Ahmed H, Aabdelwahab MB (2016) Stepwise Management of Necrotizing Enterocolitis Could Improve Outcome of this Life-Threatening Disease. Med Rep Case Stud 1: 113. doi: 10.4172/2572 5130.1000113

Copyright: () 2016 Abdel Maksod YH, et al. This is an open-access article distributed under the terms of the Creative Commons Attribution License, which permits unrestricted use, distribution, and reproduction in any medium, provided the original author and source are credited. 
$[11,12]$. The options for surgical interference range between primary peritoneal drainage and laparotomy. However, the optimum choice between both also remains undetermined [13]. The current prospective study aimed to present various lines of management of infants with NEC and to outline its outcome.

\section{Patients and Methods}

The current prospective study was conducted at Neonatal Intensive Care Unit of Pediatric Department and Pediatric Surgery Unit of General Surgery Department at El noor, Bin laden Hospitals, KAS since Jan 2009 till Jan 2014. The study protocol was approved by the Local Ethical Committee and parents of the enrolled neonates signed fully informed consent prior to enrollment. Infants had any major gastrointestinal anomalies or had undergone abdominal surgery before enrollment or their parents refused to sign the consent were not enrolled in the study.

The study aimed to include infants with suspected or confirmed NEC who met even one of historical, clinical or radiological criteria for diagnosis of NEC as documented by Bell et al. [14]. Historical criteria include feeding intolerance, apneic/bradycardic episodes, oxygen desaturation, or grossly blood stools. Clinical criteria include abdominal distention, capillary refill time $>2$ seconds, abdominal wall discoloration, or abdominal tenderness. All patients underwent serial plain X-ray abdominal films in both supine postero-anterior and lateral decubitus positions for assessment of presence of pneumatosis intestinalis (PI), dilated bowel, portal venous air (PVA), ileus, pneumoperitoneum, air/fluid levels, thickened bowel walls, ascites, peritoneal fluid, or abnormal bowel gas pattern. Pneumatosis intestinalis (PI) was graded according to Voss et al. [15] as mild (grade I) if confined to one quadrant, moderate (grade II) if confined to 2-3 quadrants and severe (grade III) if present in the four abdominal quadrants; absence of PI was graded as grade 0. Enrolled infants were staged according to Walsh and Kliegman modified Bell Staging criteria [16] as shown in Table 1.

Pre-enrolment data included demographic, maternal, prenatal, and intrapartum data, medication history (for both mother and child), and newborn history including mode of feeding (parenteral or enteral), method (bolus or continuous), type of enteral nutrition (breast milk, formula, or a combination), volume of formula, and the weight of the infant. After study entry, detailed clinical data were collected daily until infants underwent surgery, reached full feedings, received another diagnosis, or died. If an operation was performed, surgical findings were recorded and data on postoperative course were collected.

All neonates were managed at NICU. Medical management included the following items no oral feeding, gastric suction, parentral nutrition, intravenous broad spectrum antibiotic therapy, cardiorespiratory support, follow-up by serial estimation of blood gases, platelet count and complete blood count and serial abdominal X-ray studies.
The applied feeding program relied on parentral feeding till patients start to thrive. Parentral nutrition was adjusted to start with 2-3 gm of amino acids $/ \mathrm{kg} /$ day and increased gradually during a period of one week as recommended by Koletzko et al. [17]. Such dose of parentral amino acids was documented to be well tolerated with no significant acidosis or hyperamonia $[18,19]$. As regards carbohydrate infusion; lower glucose infusion rates of $3.5 \mathrm{mg} / \mathrm{kg} / \mathrm{min}(6 \mathrm{~g} / \mathrm{kg} /$ day $)$ are initially given, usually in solutions with $5 \%$ dextrose to guard against development of hyperglycemia, then rate was increased to rates of 4-7 mg/kg/min which are appropriate for most newborns [20,21].

Then, enteral feeding was tried as a test for feeding tolerance without early shift or delay and was started with mothers' milk given gradually according to the following regimen $5 \mathrm{ml} / \mathrm{kg} /$ day for 5 days for infants $<1000$ grams, $10 \mathrm{ml} / \mathrm{kg} /$ day for 2 days for infants $1000-1500$ grams and $20 \mathrm{ml} / \mathrm{kg} / \mathrm{day}$ for one day for infants $>1500$ grams. If tolerated the amount and frequency were increased according to patients' response; if not parentral nutrition was re-instituted [22].

Pneumoperitoneum is considered as an absolute indication for surgical intervention. Relative indications for emergency surgical interference included clinical deterioration despite supportive care, evidence of peritonitis indicating gangrenous bowel, associated perforation, and evidence of intestinal obstruction, persistent thrombocytopenia, or neutropenia.

For non-responders to medical intervention, bedside diagnostic mini-laparoscopy was performed in the NICU under intravenous fentanyl anesthesia with vecuronium muscle paralysis. With the patient in supine position and after skin preparation of the abdomen, induction of $\mathrm{CO}_{2}$ pneumoperitoneum through a previously installed infra-umbilical midline $3 \mathrm{~mm}$ port using the open technique was done, with a maximum pressure of $10 \mathrm{mmHg}$ and maximal flow rate of $2 \mathrm{~L} / \mathrm{min}$. A 3-mm 30 degree telescope has been used to explore the peritoneal cavity. Under direct laparoscopic guidance, a 3-mm working trocar was applied in the right or the left lumbar regions depending on the intraoperative findings, through which suction/irrigation was done with the application of intra-peritoneal drainage, using Penrose drain positioned in one of the port sites. If no intestinal perforation was detected and/or if no improvement was observed, patients were prepared for exploratory laparotomy.

Exploratory laparotomy was done, whenever indicated, through supra-umbilical transverse incision, peritoneal fluid collections were taken for bacteriological examination and surgical decision was taken according to degree of tissue affection. In cases with localized disease, bowel resection and primary anastomosis was performed or resection of necrotic segment and exteriorization of viable ends as stoma in those with long intestinal segment necrosis. For cases of pan-necrosis only peritoneal lavage and drainage was performed.

Postoperative care was provided at NICU with patient maintained on ventilatory cardio-respiratory support, appropriate parentral

\begin{tabular}{|l|l|l|l|}
\hline Stage & Systemic signs & Intestinal signs \\
\hline $\begin{array}{l}\text { IA } \\
\text { (Suspected) }\end{array}$ & $\begin{array}{l}\text { Temperature instability, apnea, } \\
\text { bradycardia, lethargy }\end{array}$ & $\begin{array}{l}\text { Poor feeding, emesis, pre-gavage residuals, mild } \\
\text { abdominal distension }\end{array}$ & Normal, or intestinal dilatation, mild ileus \\
\hline IB (Suspected) & As IA + blood from rectum \\
\hline II A (Proven) & $\begin{array}{l}\text { As IB + absent bowel sounds, mild abdominal tenderness } \\
\text { As above + metabolic acidosis, } \\
\text { thrombocytopenia }\end{array}$ & $\begin{array}{l}\text { As IA + absent abdominal sounds, definite abdominal } \\
\text { tenderness }\end{array}$ & As IIA + PVA + possible ascites \\
\hline III A (Advanced) & As IIB+ hypotension, respiratory & As IIB + peritonitis, marked abdominal distension & As IIA + PVA + definite ascites \\
\hline III B (Advanced) & acidosis, neutropenia & As IIIA + pneumoperitoneum \\
\hline
\end{tabular}

Table 1: Modified Bell's criteria according to Walsh and Kliegman [16]. 
antibiotic therapy, oral decompression, adequate fluid and electrolyte replacement and then parentral nutrition was supplied. Six-weeks after initial laparotomy and disappearance of clinical and radiological signs of NEC, patients with stoma underwent laparotomy for intestinal reanastomosis to regain intestinal continuity.

\section{Statistical Analysis}

Obtained data were presented as mean $\pm \mathrm{SD}$, ranges, numbers and ratios. Results were analyzed using Chi-square test $\left(\mathrm{X}^{2}\right.$ test). Statistical analysis was conducted using the SPSS (Version 15, 2006) for Windows statistical package. $P$ value $<0.05$ was considered statistically significant.

\section{Results}

The study included 127 neonates presented with variable clinical data suggestive of possibility of NEC. Details of maternal and neonatal data are shown in Table 2.

At admission, all patients were anemic, had leucocytosis and low platelet count. Radiological work-up detected pneumoperitoneum in 26 patients, portal vein air in 13 patients and 105 patients had pneumatosis intestinalis (PI); 32 had PI-grade I, 55 had PI-grade II and 18 had PI-grade III. Echocardiography detected patent ductus arteriosus in 65 patients. Details of laboratory and radiological findings of enrolled neonates are shown in Table 3.

Thirty-nine patients $(30.7 \%)$ underwent emergency surgical exploration; 26 patients had pneumoperitoneum and 13 patients had portal vein air. Details of findings on laparotomy and procedures undertaken are shown in Table 4.

Eighty-eight cases were managed conservatively; 54 cases responded to medical treatment and tolerated oral feeding within a mean duration of $39.3 \pm 8.4$; range: $25-56$ days. Unfortunately, 34 cases

\begin{tabular}{|c|c|c|c|c|}
\hline \multicolumn{4}{|l|}{ Data } & Findings \\
\hline \multirow{5}{*}{$\begin{array}{l}\text { Maternal } \\
\text { data }\end{array}$} & \multirow{2}{*}{\multicolumn{2}{|c|}{ Age (years) }} & $<30: \geq 30$ & $83: 44$ \\
\hline & & & Mean $( \pm$ SD) & $29 \pm 4.6$ \\
\hline & \multirow{2}{*}{\multicolumn{2}{|c|}{$\begin{array}{l}\text { Pregnancy-related } \\
\text { diseases }\end{array}$}} & Hypertension & $32(25.2 \%)$ \\
\hline & & & Diabetes & $13(10.2 \%)$ \\
\hline & \multicolumn{2}{|c|}{ Mode of delivery } & Vaginal: CS & $56: 71$ \\
\hline \multirow{18}{*}{$\begin{array}{l}\text { Neonatal } \\
\text { data }\end{array}$} & \multicolumn{2}{|l|}{ Gender } & $\mathrm{M}: \mathrm{F}$ & $84: 43$ \\
\hline & \multirow{2}{*}{\multicolumn{2}{|c|}{ GA (weeks) }} & $<30: \geq 30$ & 43:91 \\
\hline & & & Mean $( \pm S D)$ & $28.3 \pm 2.8$ \\
\hline & \multirow{2}{*}{\multicolumn{2}{|c|}{ Birth weight (gm) }} & $<1250: \geq 1250$ & $75: 52$ \\
\hline & & & Mean $( \pm S D)$ & $1300.5 \pm 205.1$ \\
\hline & \multirow{13}{*}{$\begin{array}{l}\text { Clinical } \\
\text { data }\end{array}$} & \multirow{4}{*}{$\begin{array}{l}\text { At time of } \\
\text { delivery }\end{array}$} & Intubation & $81(63.6 \%)$ \\
\hline & & & Use of resuscitation drugs & $23(18.1 \%)$ \\
\hline & & & Use of surfactant & $87(68.5 \%)$ \\
\hline & & & Use of steroid & $16(12.6 \%)$ \\
\hline & & \multirow{4}{*}{$\begin{array}{l}\text { Mode of } \\
\text { feeding }\end{array}$} & Breast & $44(34.6 \%)$ \\
\hline & & & Formula & $51(40.2 \%)$ \\
\hline & & & Nothing & $32(25.2 \%)$ \\
\hline & & & Parentral & $65(51.2 \%)$ \\
\hline & & \multirow{2}{*}{$\begin{array}{l}\text { Prior to } \\
\text { diagnosis }\end{array}$} & Positive blood culture & $34(26.8 \%)$ \\
\hline & & & Empirical antibiotic therapy & $112(88.2 \%)$ \\
\hline & & \multirow{3}{*}{$\begin{array}{l}\text { Mode of } \\
\text { presentation }\end{array}$} & Feeding intolerance & $79(62.2 \%)$ \\
\hline & & & Abdominal distension & $110(62.2 \%)$ \\
\hline & & & $\begin{array}{l}\text { Respiratory embarrassment } \\
\text { required } \mathrm{MV}\end{array}$ & $92(72.4 \%)$ \\
\hline
\end{tabular}

Note: Data are presented as numbers \& mean \pm SD; percentages are in parenthesis; GA: Gestational age; CS: cesarean section; MV: Mechanical ventilation.

Table 2: Maternal and neonatal data of enrolled neonates.

\begin{tabular}{|c|c|c|c|}
\hline \multicolumn{3}{|l|}{ Data } & \multirow{2}{*}{$\begin{array}{c}\text { Findings } \\
82: 45\end{array}$} \\
\hline \multirow{7}{*}{$\begin{array}{l}\text { Laboratory } \\
\text { findings }\end{array}$} & \multirow{2}{*}{$\begin{array}{l}\text { Hemoglobin concentration } \\
(\mathrm{gm} \%)\end{array}$} & $\leq 7:>7$ & \\
\hline & & Mean $( \pm S D)$ & $7.3 \pm 1$ \\
\hline & \multirow[t]{2}{*}{ TLC (x1000 cells/cc) } & $<10: \geq 10$ & 33: 94 \\
\hline & & Mean $( \pm S D)$ & $10.865 \pm 1.35$ \\
\hline & \multirow[t]{2}{*}{ Platelet (x1000 platelet/cc) } & $<120: \geq 120$ & 39: 88 \\
\hline & & Mean $( \pm \mathrm{SD})$ & $153.2 \pm 4.91$ \\
\hline & Acidosis & Yes: No & 98: 88 \\
\hline \multirow{7}{*}{$\begin{array}{l}\text { Radiological } \\
\text { findings }\end{array}$} & Pneumoperitoneum & Yes: No & $26: 101$ \\
\hline & Portal vein air & Yes: No & 13: 114 \\
\hline & \multirow[t]{4}{*}{$\mathrm{PI}$} & No & $22(17.3 \%)$ \\
\hline & & Grade I & $32(25.2 \%)$ \\
\hline & & Grade II & $55(43.3 \%)$ \\
\hline & & Grade III & $18(14.2 \%)$ \\
\hline & \multicolumn{2}{|l|}{ Patent ductus arteriosus } & 65 (51.2\%) \\
\hline
\end{tabular}

Note: Data are presented as numbers, ratios and mean $\pm S D$; percentages are in parenthesis; TLC: total leucocytic count; PI: Pneumatosis intestinalis.

Table 3: At NICU admission laboratory and radiological findings.

failed to respond to conservative medical treatment and underwent bed-side laparoscopy. Bed-side laparoscopy was therapeutic in 10 cases $(11.4 \%)$ and preparatory for emergency laparotomy in 6 cases $(6.8 \%)$ and reduced the need for urgent laparotomy in 18 cases $(20.5 \%)$. Detailed laparoscopic findings and procedures applied are shown in Table 5.

Collectively; the underlying pathology, of the seventy-three (57.5\%) patients who were managed through either laparotomy or laparoscopy was intestinal pan-necrosis in 14 patients (19.2\%), long-segment intestinal necrosis in 10 patients (13.7\%), multiple small intestinal perforation in 17 patients $(23.3 \%)$, single intestinal perforation in 8 patients $(11 \%)$, generalized peritonitis in 12 patients $(16.4 \%)$ and localized peritonitis in $12(16.4 \%)$ patients.

Concerning short-term outcome; 57 patients (55.7\%) passed uneventful post-interventional course, tolerated oral feeding and started to thrive; 35 of the responders to medical intervention and 22 after surgical interference, 8 after therapeutic laparoscopy and 14 after laparotomy, with significantly $\left(\mathrm{X}^{2}=9.281, \mathrm{p}<0.01\right)$ higher frequency of success among patients had medical intervention. Seventy patients developed additional morbidities during their post-interventional course; 19 after medical and 51 after surgical intervention with significantly $\left(\mathrm{X}^{2}=3.16, \mathrm{p}<0.05\right)$ lowers frequency of development of additional morbidities among patients had medical intervention. Unfortunately, 35 patients died throughout their post-interventional course; 5 after medical and 30 after surgical intervention with significantly $\left(\mathrm{X}^{2}=3.827, \mathrm{p}<0.05\right)$ lowers mortality among patients had medical intervention.

Postoperative additional morbidities included 31 surgeryrelated morbidities and $20 \mathrm{PO}$ medical morbidities. Surgery-related morbidities included wound infection in 18 cases and were managed conservatively in 15 patients and required drainage in 3 patients, but all responded to treatment. Eight patients had partial wound disruption and were managed conservatively till healing by secondary intention in 6 patients, while two patients required debridement and closure by secondary sutures. Three patients had stomal prolapse without discoloration and were reduced under light inhalational anesthesia and circulage suture was applied to prevent re-prolapse. Two patients had stomal stricture and were dilated under anesthesia with tube insertion. PO medical morbidities included chest infection in 10 
Citation: Abdel Maksod YH, Shahin AM, Ahmed H, Aabdelwahab MB (2016) Stepwise Management of Necrotizing Enterocolitis Could Improve Outcome of this Life-Threatening Disease. Med Rep Case Stud 1: 113. doi: 10.4172/2572-5130.1000113

\begin{tabular}{|l|l|l|}
\hline Laparotomy findings & Procedure & Number (\%) \\
\hline Pan-intestinal gangrene with necrosis of unresectable intestine & Only peritoneal drainage \\
\hline Necrosis of long-jejunal segment & $\begin{array}{l}\text { Peritoneal lavage, intestinal resection and anastomosis without intestinal } \\
\text { diversion }\end{array}$ & $\begin{array}{l}\text { Peritoneal lavage, multiple-segment resection and anastomosis without } \\
\text { diversion }\end{array}$ \\
\hline Multiple small intestinal perforations & 6.3\%) \\
\hline $\begin{array}{l}\text { Localized small intestinal perforation with patches of covering } \\
\text { pyogenic membrane; no gangrene }\end{array}$ & Peritoneal lavage, intestinal resection and direct closure \\
\hline \begin{tabular}{l} 
Right colonic perforation \\
\hline Gangrenous gall bladder with jejunal loops mass
\end{tabular} & Peritoneal lavage, right colectomy and anastomosis with diverting iliostom \\
\hline Total & Peritoneal lavage and drainage \\
\hline
\end{tabular}

Note: Data are presented as numbers; percentages are in parenthesis.

Table 4: Laparotomy findings and procedures applied for 39 patients had emergency surgery.

\begin{tabular}{|l|l|l|}
\hline Laparoscopy findings & Procedure \\
\hline Pan-intestinal gangrene with necrosis of unresectable intestine & Only peritoneal lavage and drainage \\
\hline $\begin{array}{l}\text { Generalized peritonitis mostly due to intestinal perforations with the } \\
\text { intestine was amalgamated }\end{array}$ & $\begin{array}{l}\text { Only peritoneal lavage and drainage because of hazardous } \\
\text { exploration and was postponed }\end{array}$ \\
\hline Localized peritonitis & $\begin{array}{l}\text { Peritoneal lavage, small single intestinal perforation was detected } \\
\text { and managed laparoscopically with in situ drainage }\end{array}$ \\
\hline Long-segment necrosis & Open peritoneal lavage, intestinal resection and direct closure \\
\hline Multiple perforations & & 12 (35.3\%) \\
\hline
\end{tabular}

Note: Data are presented as numbers; percentages are in parenthesis.

Table 5: Outcome of conservative medical and laparoscopic management of 88 patients.

patients, hyperglycemia in 5 patients, circulatory failure in patients and 2 patients developed coagulopathy.

As regards postoperative mortality; all patients had pan-intestinal necrosis $(\mathrm{n}=14)$ died during their postoperative course. The remaining mortalities included 5 patients had multiple resections for multiple perforations, 2 had long-segment necrosis, 2 patients had gall perforation, 2 had generalized peritonitis and one had colonic resection. Both patients who had developed coagulopathy, one with circulatory collapse and another patient developed ventilatorassociated pneumonia failed to respond to treatment and died.

Concerning patients underwent medical intervention, chest infection was the most frequent morbidity confronted and occurred in 13 patients and was controlled in 11 patients but progressed in 2 mechanically ventilated patients to ventilator associated pneumonia and unfortunately died. Three patients developed circulatory collapse, two patients developed hyperglycemia and another patient developed coagulopathy. Both of patients with circulatory collapse and that with coagulopathy failed to respond to treatment and died.

\section{Discussion}

The study included 127 NEC patients; 39 patients required emergency surgical interference, while 88 patients underwent the medical intervention trial. Fifty-four cases (61.4\%) responded to medical treatment and tolerated oral feeding within a mean duration of $39.3 \pm 8.4$ days. Thirty-four cases failed to respond to medical intervention and underwent bed-side laparoscopy that was therapeutic in 10 cases $(11.4 \%)$ and preparatory for emergency laparotomy in 6 cases $(6.8 \%)$ and reduced the need for urgent laparotomy in 18 cases $(20.5 \%)$.

Concerning short-term outcome; 57 patients (55.7\%) passed uneventful post-interventional course, tolerated oral feeding and started to thrive; 35 of the responders to medical intervention, 8 after therapeutic laparoscopy and 14 after surgical intervention. Seventy patients developed additional morbidities; 19 after medical and 51 after surgical intervention; unfortunately, 35 patients died; 5 after medical and 30 after surgical intervention with significantly higher success rate and lower morbidity and mortality rates among patients had medical intervention compared to patients had surgical intervention.

The reported outcome of surgical management go in hand with Abdullah et al. [23] who reviewed medical databases through 1997 till 2003 and found surgically managed patients had greater length of stay, and total hospital mortality. Garcia et al. [24] found morbidities during the first year of life were related to surgery where the reported high survival rate during neonatal period, diminished in the first year of life.

Murthy et al. [25] documented that after surgery for NEC, the short-term outcomes are grave, particularly for infants born $<28$ weeks gestation and analyses to predict outcomes suggest that surgically managed infants are at a high risk for lengthy hospitalizations and adverse medical and neuro-developmental abnormalities. Hull et al. [26] through a national body weight (BW)-based study for the mortality of NEC in 655 US centers that prospectively evaluated 188,703 verylow BW neonates between 2006 and 2010, reported that the frequency of NEC was $9 \%$ and total mortality rate was $28 \%$ among NEC patients and mortality rates were $21 \%$ in patients managed medically and $35 \%$ in those managed surgically.

Concerning surgical decision making, Kelleher et al. [27] found no difference in mortality or survival with intestinal failure between peritoneal drainage and laparotomy in infants with surgical NEC. Also, Hull et al. [26] found laparotomy alone and drainage with laparotomy groups had similar mortalities.

In line with outcome of laparoscopic management; Nah et al. [28] documented that diagnostic laparoscopy allows precise identification of perforation site and to perform a limited micro-laparotomy, thus significantly reducing the surgical trauma. Corona Bellostas et al. [29] also, found laparoscopy avoided laparotomy in patient who did well after washing and drainage, excluded lesions in patients who did not require laparotomy after intestinal bypass, and in other cases, 
Citation: Abdel Maksod YH, Shahin AM, Ahmed H, Aabdelwahab MB (2016) Stepwise Management of Necrotizing Enterocolitis Could Improve Outcome of this Life-Threatening Disease. Med Rep Case Stud 1: 113. doi: 10.4172/2572-5130.1000113

laparoscopy was followed by mini-laparotomy oriented to the lesions and stoma formation. Smith and Thyoka [30] reviewed published literature for the use of laparoscopy for management of acute NEC and reported that $18 \%$ of infants did not require further surgery following laparoscopy, $9 \%$ had no evidence of NEC, $5 \%$ had no evidence of perforation or intestinal gangrene, and $5 \%$ had NEC totalis precluding further surgery and concluded that laparoscopy can be useful in babies with suspected NEC to avoid unnecessary laparotomy and minimize surgical trauma.

For patients underwent medical intervention, the applied feeding program relied on parentral feeding, while oral feeding was prohibited, till patient started to thrive and tested for enteral feeding tolerance by one-week increments of amount of oral intake. In support of the rational of gradual establishment of oral feeding, Wang et al. [31] found that among preterm infants with $\mathrm{GA}<32$ weeks positive nutritional support allowed significantly shorter time for gaining weight, duration of intravenous nutrition, time to full enteral feeding, and length of hospital stay with significantly lower incidence of feeding intolerance and sepsis than those maintained on traditional nutritional program.

Recently, Morgan et al. [32] through clinical trials databases search reported that advancing enteral feed volumes at daily increments of 30$40 \mathrm{ml} / \mathrm{kg}$ does not increase the risk of NEC or death in VLBW infants compared to $15-24 \mathrm{ml} / \mathrm{kg}$. Park et al. [33] documented that extremely preterm infants gradually achieved feeding milestones; but attainment of the feeding milestones slowed significantly for infants with younger birth GA and the presence of medical complications.

Mother's milk was used for cases started oral feeding, reliance on human breast milk go in hand with Maayan-Metzger et al. [34] who retrospectively detected lower rates of NEC and retinopathy of prematurity in infants born at 24-28 weeks' GA and fed human milk. Downard et al. [35] documented that the Cochrane Reviews support the use of prophylactic probiotics in preterm infants $<2500$ grams, as well as the use of human breast milk rather than formula when possible.

Seigel et al. [36] found initiating oropharyngeal colostrums in VLBW infants in the first 2 postnatal days appears feasible and safe and may be nutritionally beneficial. Gane et al. [37] documented that antenatal steroids and breast feeding had beneficial effects. Park et al. [33] found infants fed with breast milk achieved each of five feeding milestones earlier than formula-fed infants. In support of use of breast milk, Salvatori et al. [38] documented that the best option for surgical term and preterm newborns is to offer them their own mother's milk through the promotion and support of breastfeeding.

In trial to explore the mechanisms underlying the beneficial effect of breast milk; Guner et al. [39] attributed the protective effect of breast milk to the cytoprotective effect of epidermal growth factor (EGF), which is found in high levels in breast milk on the intestinal epithelium. Good et al. [40] experimentally found the lipopolysaccharide receptor Toll-like receptor 4 (TLR4) plays a critical role in NEC development via deleterious effects on mucosal injury and repair and indicated that the protective effect of breast milk occurred via inhibition of enterocyte apoptosis and restoration of enterocyte proliferation through inhibition of TLR4 signaling via EGF/EGFR activation and glycogen synthase kinase- $3 \beta$ inhibition.

It could be concluded that medical treatment and early gradual entral feeding with breast milk provided success rate of $61.4 \%$. Bed-side laparoscopy could be used as preparatory procedure for emergency laparotomy and reduced the need for urgent laparotomy and acted well as a therapeutic modality for NEC patients failed to respond to medical intervention. Mortality rate was significantly higher with surgical interference, so could be preserved for cases had indication for emergency surgery, diagnosed by laparoscopy or failed to respond to medical and supportive therapy.

\section{References}

1. Obladen M (2009) Necrotizing enterocolitis-150 years of fruitless search for the cause. Neonatology 96: 203-210.

2. Youn YA, Kim EK, Kim SY (2015) Necrotizing enterocolitis among very-lowbirth-weight infants in Korea. J Korean Med Sci 30: S75-S80.

3. Horton KK (2005) Pathophysiology and current management of necrotizing enterocolitis. Neonatal Netw 24: 37-46.

4. Neu J (2005) Neonatal necrotizing enterocolitis: An update. Acta Paediatr 94 100-105.

5. Salhab WA, Perlman JM, Silver L, Broyles RS (2004) Necrotizing enterocolitis and neurodevelopmental outcome in extremely low birth weight infants $<1000$ g. J Perinatol 24: 534-540.

6. Watkins DJ, Besner GE (2013) The role of the intestinal microcirculation in necrotizing enterocolitis. Semin Pediatr Surg 22: 83-87.

7. Choi YY (2014) Necrotizing enterocolitis in newborns: update in pathophysiology and newly emerging therapeutic strategies. Korean J Pediatr 57: 505-513.

8. Ng PC (2014) Biomarkers of necrotising enterocolitis. Semin Fetal Neonata Med 19: 33-38.

9. De Plaen IG (2013) Inflammatory signaling in necrotizing enterocolitis. Clin Perinatol 40: 109-124.

10. Kasivajjula H, Maheshwari A (2014) Pathophysiology and current management of necrotizing enterocolitis. Indian J Pediatr 81: 489-497.

11. Thoene M, Hanson C, Lyden E, Dugick L, Ruybal L, et al. (2014) Comparison of the effect of two human milk fortifiers on clinical outcomes in premature infants. Nutrients 6: 261-275.

12. Lau CS, Chamberlain RS (2015) Probiotic administration can prevent necrotizing enterocolitis in preterm infants: A meta-analysis. J Pediatr Surg 50: 1405-1412.

13. Fisher JG, Jones BA, Gutierrez IM, Hull MA, Kang KH, et al. (2014) Mortality associated with laparotomy-confirmed neonatal spontaneous intestinal perforation: a prospective 5-year multicenter analysis. J Pediatr Surg 49: 1215-1219.

14. Bell MJ, Ternberg JL, Feigin RD, Keating JP, Marshall R, et al. (1978) Neonatal necrotizing enterocolitis: Therapeutic decisions based upon clinical staging Ann Surg 187: 1-7.

15. Voss M, Moore SW, Merwe VD, Pieper C (1998) Fulminating necrotizing enterocolitis: outcome and prognostic factors. Pediatr Surg Int 13: 576-580.

16. Walsh MC, Kliegman RM (1986) Necrotizing enterocolitis: Treatment based on staging criteria. Pediatr Clin North Am 33: 179-201.

17. Koletzko B, Goulet O, Hunt J, Krohn K, Shamir R (2005) Guidelines on paediatric parenteral nutrition of the European Society of Paediatric Gastroenterology, Hepatology and Nutrition (ESPGHAN) and the European Society for Clinical Nutrition and Metabolism (ESPEN), Supported by the European Society of Paediatric Research (ESPR). J Pediatr Gastroenterol Nutr 41: S1-87.

18. Porcelli Jr PJ, Sisk PM (2002) Increased parenteral amino acid administration to extremely low-birth-weight infants during early postnatal life. J Pediatr Gastroenterol Nutr 34: 174-179.

19. Thureen PJ, Melara D, Fennessey PV, Hay WW Jr (2003) Effect of low versus high intravenous amino acid intake on very low birth weight infants in the early neonatal period. Pediatr Res 53: 24-32.

20. Kalhan SC, Kilic I (1999) Carbohydrate as nutrient in the infant and child: range of acceptable intake. Eur J Clin Nutr 53: S94-S100.

21. Sinclair JC, Bottino M, Cowett RM (2011) Interventions for prevention of neonatal hyperglycemia in very low birth weight infants. Cochrane Database Syst Rev 10.

22. Mosqueda E, Sapiegiene L, Glynn L, Wilson-Costello D, Weiss M (2008) The early use of minimal enteral nutrition in extremely low birth weight newborns. $J$ Perinatol 28: 264-269. 
Citation: Abdel Maksod YH, Shahin AM, Ahmed H, Aabdelwahab MB (2016) Stepwise Management of Necrotizing Enterocolitis Could Improve Outcome of this Life-Threatening Disease. Med Rep Case Stud 1: 113. doi: 10.4172/2572-5130.1000113

Page 6 of 6

23. Abdullah F, Zhang Y, Camp M, Mukherjee D, Gabre-Kidan A, et al. (2010) Necrotizing enterocolitis in 20,822 infants: analysis of medical and surgical treatments. Clin Pediatr (Phila) 49: 166-171.

24. García H, Franco-Gutiérrez M, Gutiérrez-Hernández JI (2012) Survival and morbidity of infants with necrotizing enterocolitis treated with surgery. Rev Med Inst Mex Seguro Soc 50: 427-436.

25. Murthy K, Yanowitz TD, DiGeronimo R, Dykes FD, Zaniletti I, et al. (2014) Short-term outcomes for preterm infants with surgical necrotizing enterocolitis. J Perinatol 34: 736-740.

26. Hull MA, Fisher JG, Gutierrez IM, Jones BA, Kang KH, et al. (2014) Mortality and management of surgical necrotizing enterocolitis in very low birth weight neonates: a prospective cohort study. J Am Coll Surg 218: 1148-1155.

27. Kelleher J, Mallick H, Soltau TD, Harmon CM, Dimmitt RA (2013) Mortality and intestinal failure in surgical necrotizing enterocolitis. J Pediatr Surg 48: 568-572.

28. Nah SA, Tan HL, Tamba RP, Aziz DA, Azzam N (2011) Laparoscopic localization and microlaparotomy for focal isolated perforation in necrotizing enterocolitis: an alternative approach to a challenging problem. J Pediatr Surg 46: 424-427.

29. Corona Bellostas C, Cañizo López A, Tardáguila Calvo AR, Zornoza Moreno M, Peláez Mata D, et al. (2011) Role of laparoscopy in premature infants with suspicion of necrotizing enterocolitis. Cir Pediatr 24: 151-155.

30. Smith J, Thyoka M (2013) What role does laparoscopy play in the diagnosis and immediate treatment of infants with necrotizing enterocolitis? J Laparoendosc Adv Surg Tech A 23: 397-401.

31. Wang XM, Zhu YP, Wang L (2013) Effect of positive nutritional support strategy on extrauterine growth restriction in preterm infants. Zhongguo Dang Dai Er Ke Za Zhi 15: 1054-1058.
32. Morgan J, Young L, McGuire W (2015) Slow advancement of enteral feed volumes to prevent necrotising enterocolitis in very low birth weight infants. Cochrane Database Syst Rev 10.

33. Park J, Knafl G, Thoyre S, Brandon D (2015) Factors associated with feeding progression in extremely preterm infants. Nurs Res 64: 159-167.

34. Maayan-Metzger A, Avivi S, Schushan-Eisen I, Kuint J (2012) Human milk versus formula feeding among preterm infants: short-term outcomes. Am J Perinatol 29: 121-126.

35. Downard CD, Renaud E, St Peter SD, Abdullah F, Islam S, et al. (2012) Treatment of necrotizing enterocolitis: an American Pediatric Surgical Association Outcomes and Clinical Trials Committee systematic review. J Pediatr Surg 47: 2111-2122.

36. Seigel JK, Smith PB, Ashley PL, Cotten CM, Herbert CC, et al. (2013) Early administration of oropharyngeal colostrum to extremely low birth weight infants. Breastfeed Med 8: 491-495.

37. Gane B, Bhat BV, Adhisivam B, Joy R, Prasadkumar P, et al. (2014) Risk factors and outcome in neonatal necrotising enterocolitis. Indian J Pediatr 81: 425-428.

38. Salvatori G, Foligno S, Occasi F, Pannone V, Valentini GB, et al. (2014) Human milk and breastfeeding in surgical infants. Breastfeed Med 9: 491-493.

39. Guner YS, Chokshi N, Petrosyan M, Upperman JS, Ford HR, et al. (2008) Necrotizing enterocolitis--bench to bedside: novel and emerging strategies. Semin Pediatr Surg 17: 255-265.

40. Good M, Sodhi CP, Egan CE, Afrazi A, Jia H, et al. (2015) Breast milk protects against the development of necrotizing enterocolitis through inhibition of Tolllike receptor 4 in the intestinal epithelium via activation of the epidermal growth factor receptor. Mucosal Immunol 8: 1166-1179. 